\title{
¿Judit o Ester? \\ El Rembrandt del Museo del Prado
}

\author{
Juan María CRUZ YÁBAR \\ Conservador del Museo Arqueológico Nacional \\ juan.cruz@mecd.es
}

Entregado: 5/11/2012

Aceptado: 21/06/2013

\section{RESUMEN}

El asunto de la pintura de Rembrandt del Museo del Prado, que perteneció al secretario de Felipe IV don Jerónimo de la Torre, ha sido objeto de tres identificaciones: Artemisa, Sofonisba o Judit. Proponemos una nueva, Ester, mediante un análisis iconográfico que nos lleva a preferirla sobre Judit, que es como se designó repetidamente en la documentación histórica.

Palabras clave: Don Jerónimo de la Torre, Rembrandt, Ester, Judit.

\section{¿Judith or Esther? The Rembrandt of the Prado Museum}

\begin{abstract}
The painting by Rembrandt in the Museo del Prado, which belonged to Philip IV's secretary, don Jerónimo de la Torre, has been the object of three identifications: Artemisia, Sophonisba or Judith. We propose a new one with an iconographic analysis that get us to prefer identifying it as Esther, not Judith, despite it was mentioned like that several times in the historical documentation.
\end{abstract}

Key words: Don Jerónimo de la Torre, Rembrandt, Esther, Judith. 
El único Rembrandt del Museo Nacional del Prado (P-2132), firmado y fechado en 1634, a los pocos años de haberse establecido el pintor en Amsterdam, tiene dimensiones de 143 x 154,7 cm (Fig. 1). Muestra a una mujer sentada, ricamente vestida, que lleva la mano derecha hacia el pecho y apoya la otra en la mesa, donde se encuentra un libro abierto; una joven criada le presenta una copa de caracol marino llena de vino y otra, anciana, espera detrás con un tejido en las manos.

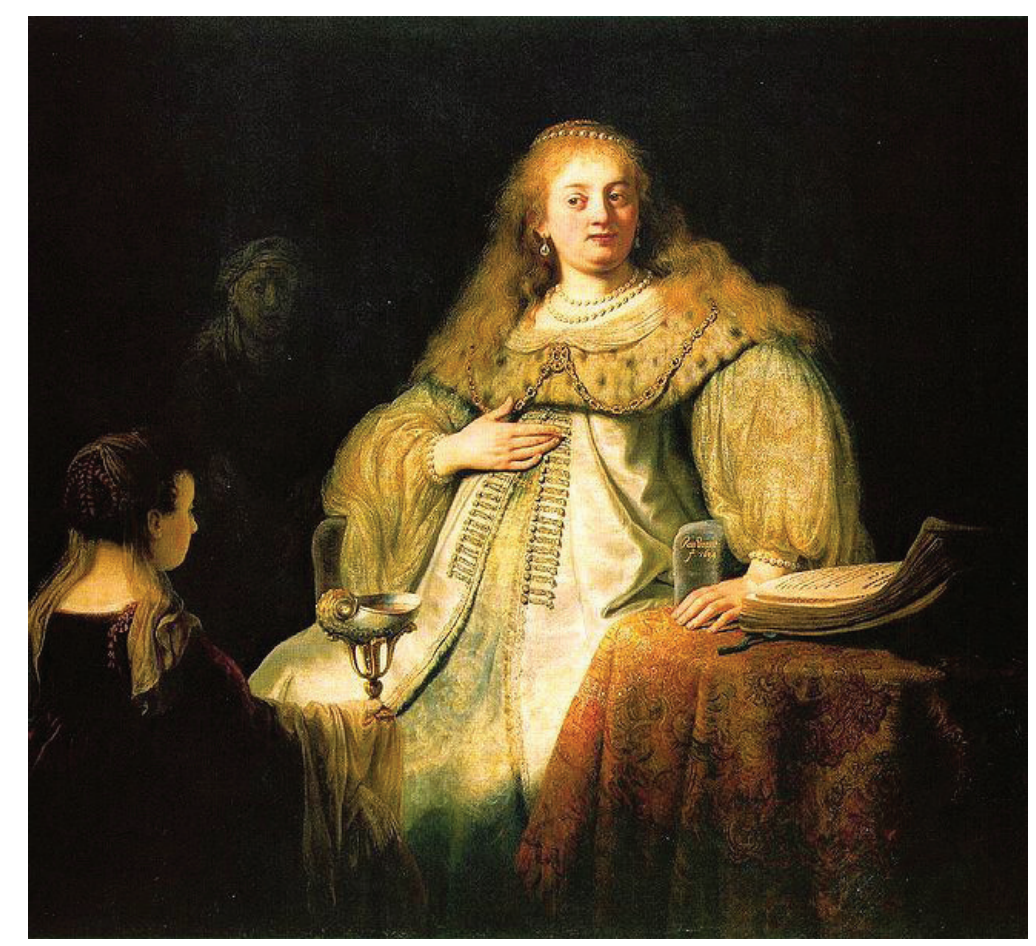

Fig. 1. Rembrandt, Ester disponiéndose a cumplir el designio de salvar a su pueblo, 1634. Museo Nacional del Prado.

En otro trabajo ${ }^{1}$ hemos demostrado que la pintura perteneció a don Jerónimo de la Torre, secretario de Estado de Felipe IV, quien la adquirió seguramente por regalo de Gaspar Roomer y Jan van den Eynden, los famosos coleccionistas flamencos residentes en Nápoles. Don Jerónimo la vinculó junto con otras 13 pinturas a su mayorazgo en su testamento del 20 de noviembre de $1658^{2}$, denominándola "otra pintura original de Judit con cornisa dorada". Es la única que no lleva en su referencia el nombre del pintor.

\footnotetext{
1 CRUZ YÁBAR, Juan María, "El rembrandt del Museo del Prado y su relación con don Jerónimo de la Torre", Boletín del Museo del Prado, 48 (2012) (en prensa).

2 Citado por ARTILES RODRÍGUEZ, Jenaro, "Una rica colección artística en Madrid (siglo XVII)", Revista de la Biblioteca, Archivo y Museo del Ayuntamiento de Madrid, 8 (1928), pp. 83-87.
} 
En 1664 presentaron las cuentas de la testamentaría ${ }^{3}$ sus hijos y albaceas don Diego, don Andrés y doña Francisca de la Torre. Se hacía allí referencia a la tasación de todas las pinturas del secretario que había hecho el 3 de septiembre de 1662 el pintor don Francisco Pérez Sierra, muy vinculado a la familia según muestran los documentos y cuenta Palomino, que era su yerno ${ }^{4}$. Aunque la tasación no aparece unida a las cuentas, se trasluce a través de éstas. Se descargan "quatro mil reales de una pintura original de Judit". Seguidamente, en la entrega de bienes a don Diego, el cuadro se cita como "La bella Judit, tasada devajo del nombre de una mujer veneciana, original, en quatro mill rreales" 5 , lo que indica que Pérez Sierra, al tasar, no había reconocido en ella a Judit, sino a una veneciana.

Don Diego, primer titular del mayorazgo, falleció en 1674 sin heredero varón, por lo que su hermano don Andrés pasó a ser el nuevo titular. En el inventario de las pinturas de don Diego, realizado por su hermano y su cuñado don Francisco Ignacio de Trasmiera en los días 1 y 2 de septiembre del citado año ${ }^{6}$ aparece de nuevo la pintura con esta mención: "Más otro cuadro de Judic de Pedro Pablo Rubenes, de siete cuartas de ancho y bara y media de alto, con su marco dorado y tallado, de una mujer, es de mayorazgo"?.

En 1684 se puso fin a una controversia que mantenían don Andrés como titular del mayorazgo y los herederos de don Diego. Se otorgó documento de partición de los bienes del difunto y se entregaron los bienes muebles de mayorazgo a don Andrés. Se copiaron las partidas del inventario hecho en 1674, con un error al llegar a la que nos interesa: "Otro cuadro del judío (sic) de Pedro Pablo Rubenes, de siette quarttas de

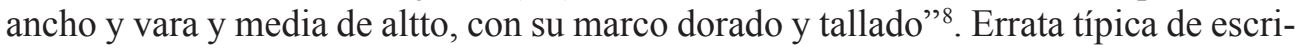
bano que copiaba una lista, pero lo suficientemente atento para ver que la referencia "de una mujer" había que suprimirla tras oir "judío".

Don Andrés de la Torre falleció en 1693. Su viuda y sobrina doña María Francisca de la Torre, hija de don Diego, casó de nuevo al año siguiente. Como nieta de don Jerónimo, se había convertido en la nueva titular del mayorazgo a falta de varón. Por ello, en el documento de promesa de dote a su segundo marido se relacionan las pinturas vinculadas ${ }^{10}$. La obra se consigna como "Otra de Judiq, tasada devajo del

3 Archivo Histórico de Protocolos de Madrid, prot 6.599, fol. 477 y ss.

4 PALOMINO, Antonio, Museo Pictórico y Escala Óptica. El Parnaso Español pintoresco y laureado, Madrid 1715-1724 [ed. Aguilar, Madrid 1947], p. 1123.

5 Archivo Histórico de Protocolos de Madrid, prot. 9.855, fol. 667-667v.

6 BURKE, Markus B. y CHERRY, Peter, Collections of Paintings in Madrid 1601-1755, Los Ángeles, 1997, t. II, pp. 653-658.

7 En la lista se incluye, en último lugar, un cuadro de Judit "copia de otra que toca al mayorazgo"; probablemente era hechura de Pérez Sierra, que ya copió los santos de Ribera para la capilla familiar (vid. CRUZ YÁBAR, Juan María, "Los cuadros de Ribera de don Jerónimo de la Torre y su capilla funeraria en el convento de los Ángeles de Madrid" (en prensa), y no es fácil que otros pintores tuvieran entrada franca en la casa de don Diego de la Torre.

8 Archivo Histórico de Protocolos de Madrid, prot. 9.869, fol. 312.

9 La copia de Judit se menciona de nuevo, valorándola ahora en 1.000 reales y adjudicándola a doña María de Zarauz, a quien correspondía un quinto de los bienes de don Diego según su testamento.

10 Archivo Histórico de Protocolos de Madrid, prot. 9.891, s. fol. 
nombre de una mujer veneziana, original, en quatro mill rreales", volviendo por tanto a la descripción y tasación de Pérez Sierra, que se copió en el documento.

Falleció doña María Francisca en 1704 y su hermana doña Jerónima lo haría cuatro años después, ambas sin descendencia; con ellas se extinguía la línea directa de sucesores de don Jerónimo de la Torre. Aunque debieron de existir pleitos con parientes de líneas colaterales por la sucesión en el mayorazgo, sus bienes quedaron en la custodia de los patronos de la fundación pía instituida por el secretario real. En 1718, los patronos decidieron recuperar las pinturas vinculadas de manos de diversas personas que las tenían, para venderlas y emplear el precio en las intenciones del fundador. Con este motivo fue llamado Teodoro Ardemans para tasar las pinturas, y el 28 de mayo suscribió su tasación. Entre las partidas aparece "Otra de la bella Judic, original de Rambran, con marco dorado y tallado, de dos baras y quarta de ancho y dos baras de alto, tasada en tres mill reales de vellón". Es la primera mención del verdadero autor de la pintura. Los patronos quedaron descontentos de la tasación y dos meses después, el 28 de julio, hicieron retasar a Antonio Palomino ${ }^{11}$, quien lo describió y tasó como "Otra pintura de la bella Judit, original de Rembran, de dos baras escasas de largo y dos menos quarta de alto, con su marco tallado y dorado, tasada en tres mill y trezientos reales".

El cuadro reaparece, según hemos explicado, entre los bienes del marqués de la Ensenada en 1754. Tras la caída en desgracia del marqués se realizó el inventario de sus bienes por orden del rey en julio de este último año. Allí se reseña, sin autor, una "Judit, de medio cuerpo" 12 , que se ha identificado con la que describió en 1768 Antonio Rafael Mengs entre los 29 cuadros de Ensenada que eligió para Carlos III como "Rembran. Un quadro de seis pies de ancho y cinco de cayda, representa a una noble matrona sentada, con ricas vestiduras y joyas y una criada que le está sirviendo una copa. Figuras de cuerpo entero y de grandeza natural. 2.500 [reales]" "13. Águeda Villar $^{14}$ localiza la pintura en los inventarios reales de 1772 y 1789 donde es citado como "Un quadro que representa a Judic, a quien unas doncellas sirven una copa, y en una mesa redonda tiene un libro abierto, figuras de más de medio cuerpo, original de Rembrandt, de siete quartas de largo y vara y media de caída".

Tras el ingreso en el Prado, sus catálogos lo denominaron Artemisa ${ }^{15}$. A finales del siglo XIX y principios del XX se registran las primeras opiniones doctrinales favorables a su identificación con Sofonisba ${ }^{16}$, que todavía mantiene el Proyecto in-

11 ARTILES RODRÍGUEZ, op . cit.

12 RODRÍGUEZ VILLA, Antonio, Don Cenón de Somodevilla, marqués de la Ensenada, Madrid, 1878, p 250.

13 ÁGUEDA VILLAR, Mercedes, "Una colección de pinturas en el Madrid del siglo XVIII: el marqués de la Ensenada" en Cinco siglos de arte en Madrid (XV-XX), Madrid, 1991, pp. 165-177.

14 EADEM.

15 MADRAZO, Pedro, Catálogo de los cuadros del Real Museo de Pinturas y Esculturas de S.M., Madrid, 1843, n 1330: "La reina Artemisa en el acto de recibir la copa que contiene mezcladas con el licor las cenizas de su marido Mausolo".

16 Así lo hicieron constar BODE, Wilhelm von, The complete work of Rembrandt, III, París 1897, pp. 125-127 y HOFSTEDE DE GROOT, Cornelis, A Catalogue raisonne of the works of the most eminent Dutch Painters of the seventeenth century based on the work of John Smith, Londres 1916, t. VI, pp. 144-145. 
ternacional de catalogación ${ }^{17}$. El último catálogo del Museo, conservando el título de Artemisa, recogía la controversia de este modo. "Se han formulado reiteradas dudas sobre el asunto representado y se ha pensado también que pudiera tratarse de Sofonisba recibiendo la copa de veneno enviada por Masinisa" ${ }^{18}$. Recientemente, Posada ${ }^{19}$ recuperó la antigua denominación de Judit para el lienzo del Prado.

Por tanto, el controvertido asunto del lienzo de Rembrandt del Museo del Prado ha conocido hasta hoy tres interpretaciones que pudiéramos calificar de oficiales: Artemisa, Sofonisba y Judit. Nos referimos a continuación a los aspectos que han intervenido de modo substancial en la identificación del personaje, bien entendido que ninguno de los estudiosos de la iconografía de esta pintura la ha puesto en relación con la que tuvo don Jerónimo de la Torre.

El secretario real la denominó Judit en su testamento porque debió de llegar a su colección con ese nombre. Pero no hay ningún elemento de la pintura que conduzca de modo seguro a tal identificación y, por ello, aunque Ardemans y Palomino la aceptaron, Francisco Pérez Sierra -que sin duda conocía el nombre que daba la familia al cuadro- la llamó "una veneciana" ${ }^{20}$. Mengs la vio en casa de Ensenada ${ }^{21}$ y le retiró el nombre de Judit para sustituirlo por el de "una matrona".

Las discrepancias son explicables. No se advierte la menor referencia a las intenciones de la heroína de matar a Holofernes, y, por el contrario, el armiño, signo de realeza, sería contradictorio con la condición plebeya de la viuda de Manasés ${ }^{22}$. Esta última objeción no existía en las dos identificaciones relacionadas con la Antigüedad clásica, ya que Artemisa y Sofonisba podían llevar armiño, porque eran reinas. Pero tampoco los personajes ni los objetos presentes en la pintura son los canónicos según su respectiva iconografía habitual. Artemisa se supone una viuda inconsolable que se hacía servir -mezcladas con agua, aunque también existían precedentes de vino- las cenizas de su marido Mausolo. No hay compunción en su rostro, ni ningún recuerdo del difunto como coraza, casco u otro objeto personal. Por lo que respecta a Sofonisba, el atavío de la dama se aviene mejor con la circunstancia, pero no hay señal de prisión ni de custodia por los romanos, y la copa con el veneno debía haber sido presentada por un soldado y no por una criada.

17 VV.AA., A Corpus of Rembrandt Paintings, La Haya, 1982-1990, t. II, A 94 y t. III, pp. 774-776.

18 Catálogo de las Pinturas. Museo del Prado, Madrid, 1996, n 3243, pp. 306-307.

19 POSADA KUBISSA, Teresa, en VERGARA, Alejandro (ed.), Rembrandt, pintor de historias, Madrid, Museo Nacional del Prado, 2008, pp. 138-142; EADEM, Pintura holandesa en el Museo del Prado, Madrid, 2009, no 46, pp. 115-125.

20 En 1674 debieron ser los testamentarios de don Diego de la Torre los que pidieron que se uniera la identificación de Pérez Sierra que figuraba en la entrega de los bienes a don Diego en 1664 junto con la de las cuentas de la testamentaría de don Jerónimo, Judit. Así quedaba claro que la Judit del testamento de éste y la veneciana de la tasación era la misma pintura.

21 La denominación del personaje por el marqués no puede explicarse por la claridad iconográfica de la pintura sino por alguna tradición, que provendría de quienes la compraron en 1718 bajo ese nombre. En las colecciones reales volvió a recuperar su antigua denominación, quizá porque alguien conocía el nombre que le daba Ensenada.

$22 \mathrm{Su}$ marido era un rico labrador que había muerto de una insolación trabajando en sus campos. 
La gran presencia del libro sobre la mesa es otro elemento extraño a las dos historias de la antigüedad clásica. Golahny ${ }^{23}$ explicó que Artemisa fue patrona de las Artes, fundadora de un agos o juego de elocuencia en elogio a Mausolo, por lo que el gesto de posar la mano izquierda sobre el libro recordaría ese patronazgo. Parece una explicación demasiado forzada, porque supondría un saber clásico muy profundo en Rembrandt que no consta que tuviera.

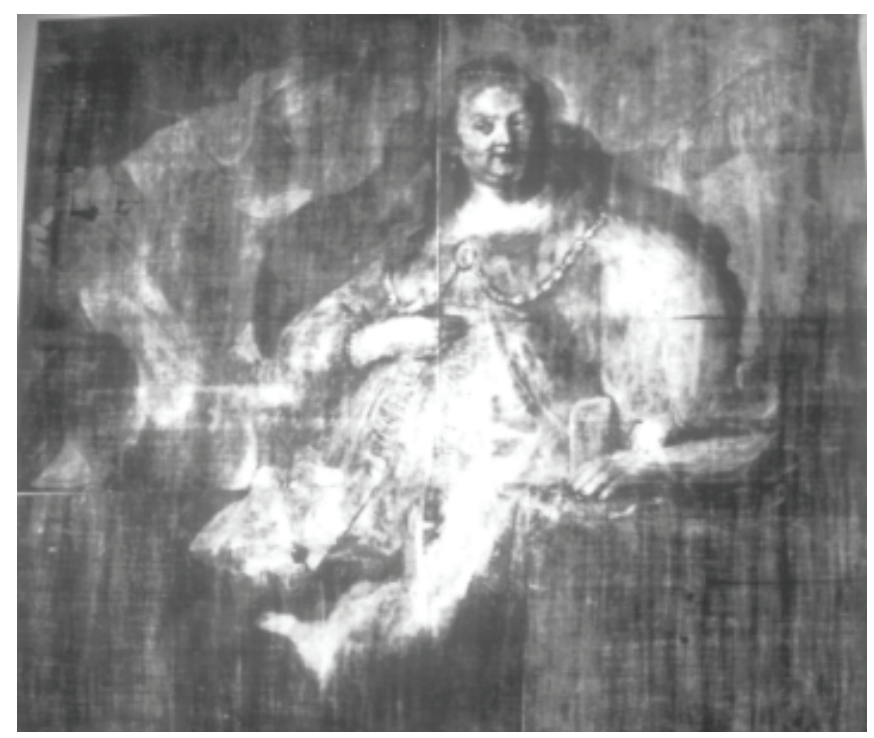

Fig. 2. Rembrandt, Ester disponiéndose a cumplir el designio de salvar a su pueblo, 1634. Museo Nacional del Prado. Radiografía.

La radiografía del lienzo (Fig. 2) muestra diferencias importantes con su aspecto actual. Se observa en el lado izquierdo una figura femenina -por la toca que le cubre la cabeza- de perfil, que se inclina ante la figura principal llevando en la mano un objeto grande y elíptico, quizá una bandeja o más probablemente un espejo. Ocupaba el lugar de la vieja que ahora asoma al fondo de la pintura con una tela en la mano. Sobre ella se extendía un cortinaje que cubría parte del extremo superior izquierdo del lienzo. La criada joven sostenía algo que parece una salva cubierta con un paño, quizá con un par de objetos encima, sin rastro de la copa. Tras la figura principal se adivinan los restos de un personaje con un tocado en la cabeza y algo grande y plano por delante. La heroína no lleva aún la estola de armiño. El libro no tenía el volumen ni la forma definitiva y la posición de la mano izquierda sobre él era menos arqueada respecto al brazo.

No cabe duda de que los elementos originarios trazados por Rembrandt respondían a la iconografía de un aseo femenino, y que el pintor cambió posteriormente su idea

23 GOLAHNY, Amy, Rembrandt's Reading. The Artist's Bookshelf of Ancient Poetry and History, Amsterdam, 2003, pp. 131-132. 


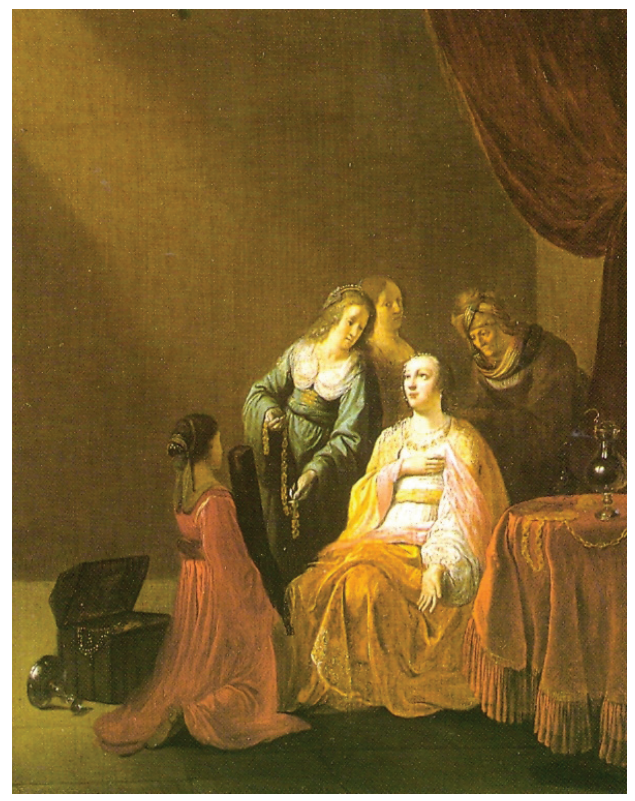

Fig. 3. Willem de Poorter, El aseo de Ester. National Gallery of Ireland.

inicial ${ }^{24}$. Diéguez ${ }^{25}$, partidaria de Sofonisba, llega a esta misma conclusión tras un bien documentado estado de la cuestión hasta 2004 y el análisis de la radiografía ${ }^{26}$. Diéguez busca en la pintura holandesa de la época los ejemplares que presenten parecido con la primera idea de la tela madrileña, y los localiza en pinturas bíblicas: $E l$ aseo de Ester o Ester preparándose para aparecer ante Asuero (National Gallery of Ireland, Dublín) (Fig. 3) del seguidor de Rembrandt Willem de Poorter (1608-1668), en la que aparece la heroína bíblica con el mismo gesto de la mano derecha y una criada joven arrodillada ante ella, que recuerda el tocado y aspecto del personaje de espaldas de la tela madrileña; El baño de Ester de Leendert de Laeff (h.1631-1661), de la colección Cambier de Bruselas, y otro Aseo de Ester o Ester preparándose para aparecer ante Asuero (colección privada) del tardío discípulo rembrandtiano Aert de Gelder (1645-1727) (Fig. 4). Y sobre todo subraya el parecido de la pintura del propio Rembrandt, El aseo de Ester o Ester preparándose para aparecer ante Asuero (The National Gallery of Canada, Ottawa), de 1633 (Fig. 5), de la que destaca el importante parecido de muchos aspectos: Ester es acicalada por una mujer mayor con turbante que arregla su pelo, mientras ella sienta ante una mesa con la mirada perdida en la lejanía, tiene el mismo gesto de su mano derecha apoyando sus dedos sobre el pecho

\footnotetext{
24 LLOYD WILliAMS, Julia, Rembrandt. Artemisa y Mujer en el lecho, cat. exp., Madrid, 2002, p. 36, no descarta la posibilidad de que la obra fuera originariamente un estudio de mujer en el tocador.

25 DIÉGUEZ RODRÍGUEZ, Ana, "Problemas iconográficos de Sofonisba recibiendo la copa de veneno de Rembrandt del Museo del Prado”, Cuadernos de Arte e Iconografia, XIII, 25 (2004), pp. 173-196.

26 La autora agradece a la restauradora doña Maite Torres su ayuda en la interpretación de la radiografía.
} 


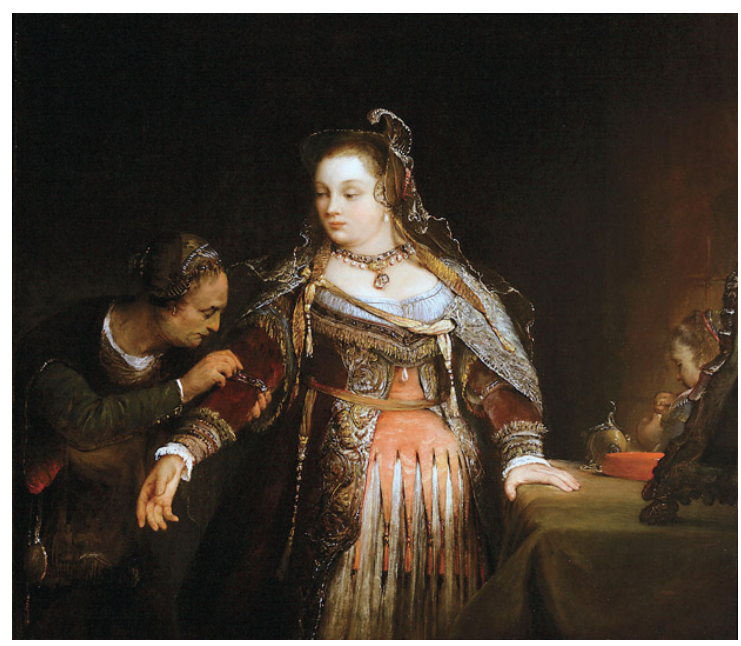

Fig. 4. Aert de Gelder, El aseo de Ester. Colección particular.

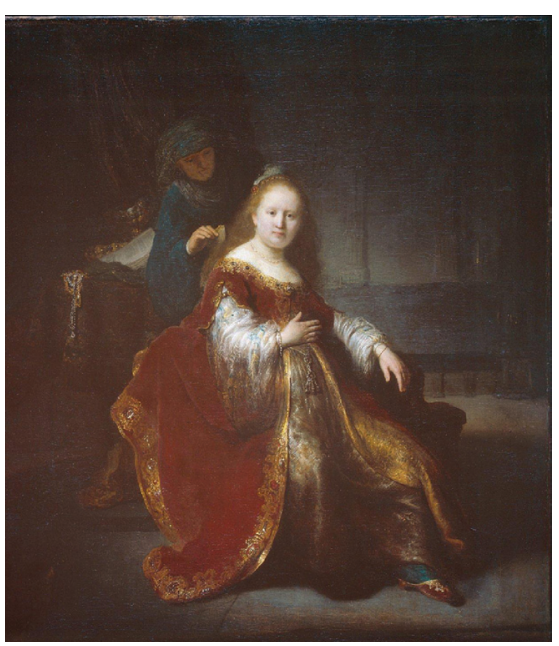

Fig. 5. Rembrandt, El aseo de Ester, 1633. The National Gallery of Canada.

y están presentes la copa sobre bandeja, el libro abierto y el cortinaje áulico tras las dos figuras ${ }^{27}$. También se refiere a la probable fuente iconográfica de estas composiciones, la estampa de Philip Galle sobre dibujo de Maarten van Heemskerck sobre la historia de Ester (1564) (Fig. 6), con parecidos elementos, destacando la presencia de una criada que lleva un manto entre las manos. Paradójicamente, después de llegar a este punto, la autora opta por identificar a la heroína con Sofonisba, a pesar de que sólo encuentra un ejemplo que presente algún paralelo con el cuadro estudiado, el óleo de Gerbrand van den Eeckhout (1621-1674) titulado Sofonisba recibiendo la copa de veneno (1664; Herzog Anton Ulrich Museum, Braunschweig), en que la reina aparece sentada mientras un soldado le ofrece la copa sobre una salvilla. Ha de forzar para ello la interpretación de la radiografía, entendiendo que el personaje que está detrás de la supuesta Sofonisba es un soldado con escudo, cuando, a nuestro entender, si lo hay, que no es claro, debe tratarse de otra criada. Piensa igualmente que la versión definitiva representa a Sofonisba.

Pasamos ahora a examinar las objeciones a que se trate de Judit. Posada se pregunta si las modificaciones de la pintura obedecen a un cambio estilístico o iconográfico, y considera que el objeto que lleva la criada desaparecida puede ser una bandeja cuyo contenido muestra a Judit, lo que, junto con el servicio de vino por la otra criada jus-

27 SLATKES, Leonard Joseph, Rembrandt. Catalogo completo, Florencia, 1992, pp. 34-35, señala la posibilidad de que se trate de un tocado de Judit, Ester o Betsabé. Para nosotros no hay duda de que se trata de Ester, porque en Judit es un asunto muy raro, como se afirma, y los cuadros de Rembrandt sobre Betsabé son dos baños (Metropolitan, de 1643, y Louvre, de 1654) en que aparece desnuda y con referencias a David, la torre desde la que la divisaba en el primero, y la carta que le envió y tiene en la mano en el segundo. También sugiere el aseo de Ester como primera idea WINKEL, Marieke de, "Artemisia (Sophonisba?)", en Rembrandt. Genie auf der Suche, cat. exp., Berlín, 2006. 


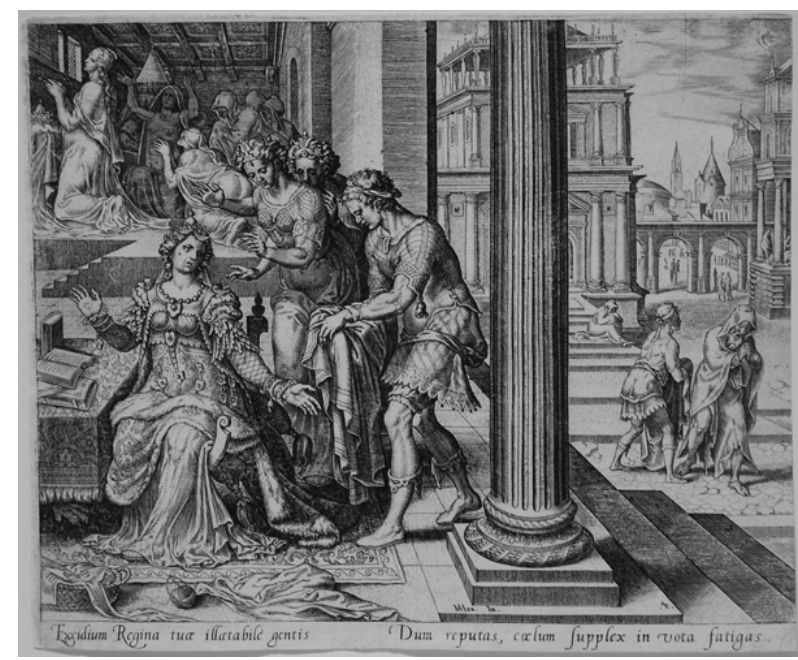

Fig. 6. Philip Galle (grabador) y Maarten van Heemskerck (inventor), Historia de Ester, 1564.

tificaría que lo representado fuera la llegada de Judit al campamento de Holofernes, ofreciéndole alimentos. Las colgaduras desaparecidas también ayudarían a sugerir la tienda donde se celebró el banquete. El libro sería una Biblia y la mirada sarcástica de la heroína la prueba de su determinación. Pero lo novedoso de la representación haría difícil identificar el asunto, y, por eso, el pintor sacrificó la figura de la criada que portaba la bandeja, sustituyéndola por la vieja criada que asoma con un saco por la puerta de la tienda, de modo que quedara algo más claro que se trataba del pasaje bíblico de Judit. Recuerda la existencia de una fuente iconográfica, la estampa de Georg Pencz (h.1500-1550), Judit en el banquete de Holofernes, en que aparece una copa sobre la mesa y la criada con un recipiente en la mano a la puerta de la tienda.

Los argumentos de Posada nos parecen poco consistentes. Ya hemos mencionado la incongruencia del armiño en su vestido y la falta de alusiones a la misión que le había llevado al campamento de Holofernes. En este sentido, la adición del armiño tras el cambio de idea ha de ser un punto importante que debe tomarse en consideración, y es obviado por Posada. En segundo lugar, tampoco la historia bíblica incluye una recepción de Holofernes a Judit a su llegada al campamento con las circunstancias que muestra la pintura y, en nuestra opinión, tampoco las reúne el banquete que le ofrecerá al cuarto día de su llegada.

El libro de Judit contiene un pasaje con una escena de aseo, en su casa de Betulia, cuando abandona sus vestidos de viuda y se reviste de las mejores galas que utilizaba cuando vivía Manasés (Judit IV, 10). En este sentido, podría tener defensa que Rembrandt hubiera empezado a pintar un aseo de Judit ayudada por tres criadas, suponiendo que una de ellas, desaparecida, quedara en discreto segundo plano, que la de la izquierda, luego sustituida, le presentara un espejo, y que la joven de espaldas le ofreciera una o dos vasijas de ungüentos en una salva. No existen precedentes 


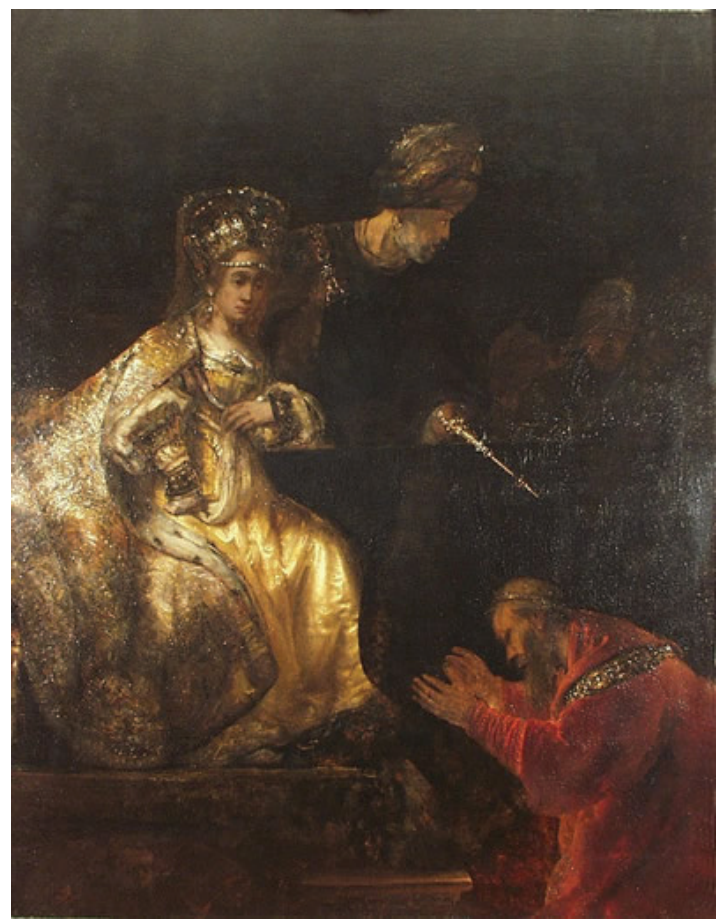

Fig. 7. Rembrandt y colaboradores, Amán implorando merced a Ester, 1635-1660. Museo Nacional de Arte de Rumanía.

de representaciones del aseo de Judit, pero no es imposible que se intentara en esta ocasión. En tal caso, ¿cuál es la escena que sustituyó al aseo? Seguimos con la historia bíblica de la heroína. Cuando Judit entró en el campamento de Holofernes, éste ofreció a la joven que comiera y bebiera de los manjares que él comía y bebía, pero Judit lo rechazó y anunció su intención de hacerlo tan sólo de las provisiones que había traído para no incurrir en falta. Al ser preguntada qué haría cuando se acabaran las provisiones, contestó que antes habría terminado su misión. Comió siempre en su tienda, servida por su criada. Al cuarto día la invitó Holofernes a un banquete que daba a sus oficiales, y Judit aceptó la invitación. Se acicaló con sus galas y acudió; la criada israelita extendió unos tapices para que pudiera reclinarse y se retiró a la puerta de la tienda, para servirle con sus provisiones (Judit IV, 12). Esta es la escena que representa la estampa de Pencz. Pero si la vieja del fondo puede ser la criada israelita, no se explica la presencia de la criada joven, pues no consta que hubiera otras mujeres en el campamento. Más extraño aún es que, en un banquete de Holofernes, no aparezca el general asirio ni ninguna referencia a él en toda la escena. Tampoco el libro tiene ninguna justificación, pues no se cita en el texto bíblico ninguna Biblia ni escrito de ningún otro tipo, ni figura por tanto en las representaciones pictóricas de Judit. Por último, hemos de recordar que el aspecto de esta pretendida Judit no responde al habitual. El aparatoso vestido no facilitaría su acción violenta y posterior 
huída. En el catálogo de Rembrandt, Judit aparece siempre con vestiduras apropiadas a su acción, con la cabeza de Holofernes en la mano o en la bolsa que lleva la sirviente mientras huyen del campamento. Así la encontramos en el dibujo del Louvre o en el más tardío de Capodimonte. La Flora de la National Gallery de Londres fue en origen una Judit con la cabeza de Holofernes y sus vestiduras eran también ligeras y adaptadas al cuerpo.

Nuestra opinión es que Rembrandt comenzó un aseo de Ester ayudada por sus criadas, asunto que, como hemos visto, no era raro en su obra ni en la pintura nórdica de la época. Por alguna razón cambió el pasaje más anecdótico del aseo por una Ester disponiéndose a cumplir el designio de salvar a su pueblo. El motivo pudo ser la petición del cliente, o simplemente, un cambio en la elección del pintor.

Lo que, a nuestro juicio, es decisivo en la cuestión, es la forma en que se narra la historia de Ester en las Antigüedades de los judios de Flavio Josefo, obra que Rembrandt tenía entre sus bienes en 1656 en edición alemana con estampas ${ }^{28}$.

Según el relato, Ester había entrado a formar parte del harén del rey Asuero sin dar a conocer su condición judía, y accedió al título de reina por haberla preferido sobre las otras mujeres. Su tío y antiguo tutor, Mardoqueo, no quiso inclinarse ante el visir Amán, por lo que éste solicitó del rey que le autorizara a dictar un decreto de exterminio del pueblo judío. Se hicieron copias del decreto para repartirlas por todo el reino y también se difundieron por la ciudad de Susa. Cuando lo supo Mardoqueo, rasgó sus vestiduras, se cubrió de saco y ceniza y se sentó a la puerta de la ciudad. Los criados de Ester se lo contaron, y ésta envió a un eunuco que le preguntara qué podía hacer por él. Mardoqueo le envió copia del decreto y le pidió que hablara al rey a favor de su pueblo; Ester le mandó responder que cualquier hombre o mujer que se presentara ante el rey sin haber sido llamado estaba condenado a morir, salvo que le tocara con su cetro de oro, y que Asuero no la había llamado a su presencia hacía treinta días. Ante la evasiva, Mardoqueo le exhortó a no pensar en su seguridad sino en la de su pueblo. Ester accedió entonces y le pidió que el pueblo judío no comiera ni bebiera y orara por ella durante tres días, que también lo haría con sus criadas; al finalizar el ayuno iría al rey, y si tenía que morir, moriría. Los judíos pidieron a Dios que les librara de la calamidad, que estaba ya ante sus ojos. El pasaje lo cuenta así: “También la reina Ester, según antigua costumbre judía, se prosternó en el suelo y se revistió con vestido de duelo; durante tres días completos se abstuvo de comida, bebida y todo placer, y rogó a Dios todopoderoso... Tras haber elevado esta oración a su divina Majestad tres días enteros, dejó el vestido lúgubre y cambió su aspecto, adornándose como corresponde a una reina, y se dirigió hacia el rey con sus damas de cámara; en una de ellas se apoyaba ligeramente, mientras que la otra la seguía levantando pulcramente con sus dedos la cola de su largo vestido" 29 . El rey, contra todo pronóstico, la recibió con cariño al verla perder las fuerzas e impuso su cetro sobre su

28 Se trata de la edición de Conrad Lautenbach con grabados según los dibujos de Tobias Stimmer: Flavij Josephi des hochberühmten Geschichtschreibers Historien und Bücher: Von alten Jüdischen Geschichten... Estrasburgo, 1574, p. 176-180. GOLAHNY, op. cit, pp 164-180, ha estudiado la incidencia de este texto en Rembrandt.

29 Flavij Josephi, op. cit., p. 177-178. 


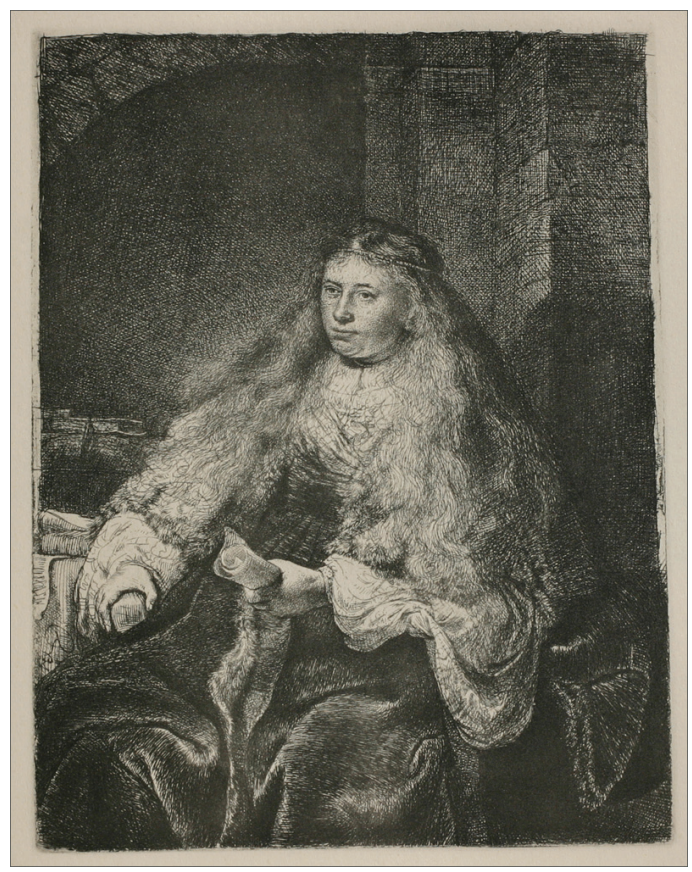

Fig. 8. Rembrandt. Ester (grabado).

cuello. Entonces, Ester solicitó del rey que acudiera al banquete que preparaba para él y para Amán. Allí, mientras bebían, volvió a invitarle de nuevo para el día siguiente, y en el curso de la comida, Ester descubrió a Amán y sus designios contra los judíos, y Asuero ordenó dar muerte al ministro y anular el decreto.

Todo en la pintura encaja con las necesidades iconográficas del pasaje. La reina Ester, ya cubierta de riquísima vestidura, con peinado meticuloso, costosas joyas entre ellas la corona o diadema real que le dio Asuero al casarse ${ }^{30}$ - y con la estola de armiño real, se dispone a llevar a cabo su arriesgada acción, un designio que acepta llevando su mano derecha al pecho ${ }^{31}$ mientras coloca su izquierda junto al decreto de exterminio al que se va a enfrentar ${ }^{32}$. La criada del fondo con el tejido entre las manos será la que sujeta la orla de su falda según el texto transcrito. La otra criada que le acompañará y en que se apoyará le ofrece una copa con el vino que le procurará la

30 IDEM, p. 176. Se ve la diadema y las perlas que dan vueltas en torno a la cabeza, es de suponer que acabando en un moño, como en el grabado del mismo año 1634 en que retrató Rembrandt a su mujer Saskia van Uylenburgh, que sirvió como preparación para esta figura de Ester.

31 El mismo gesto distingue a la heroína bíblica en Amán implorando merced a Ester (Museo Nacional de Arte de Rumanía, Bucarest) (Fig. 7), fechada hacia 1635 por especialistas holandeses por el tipo de pigmentos utilizados y repintado bastantes años más tarde (MATACHE, Maria, Maestrii Picturii Europene. Muzeul National de Arta al României, Milán, Electa, 1998, pp 142-143), donde también lleva armiño, como en las citadas pinturas del museo de Ottawa y de Poorter en Dublín, y el grabado de Galle.

32 La expresión nerviosa de boca y ojos corresponde perfectamente a su delicada misión. 


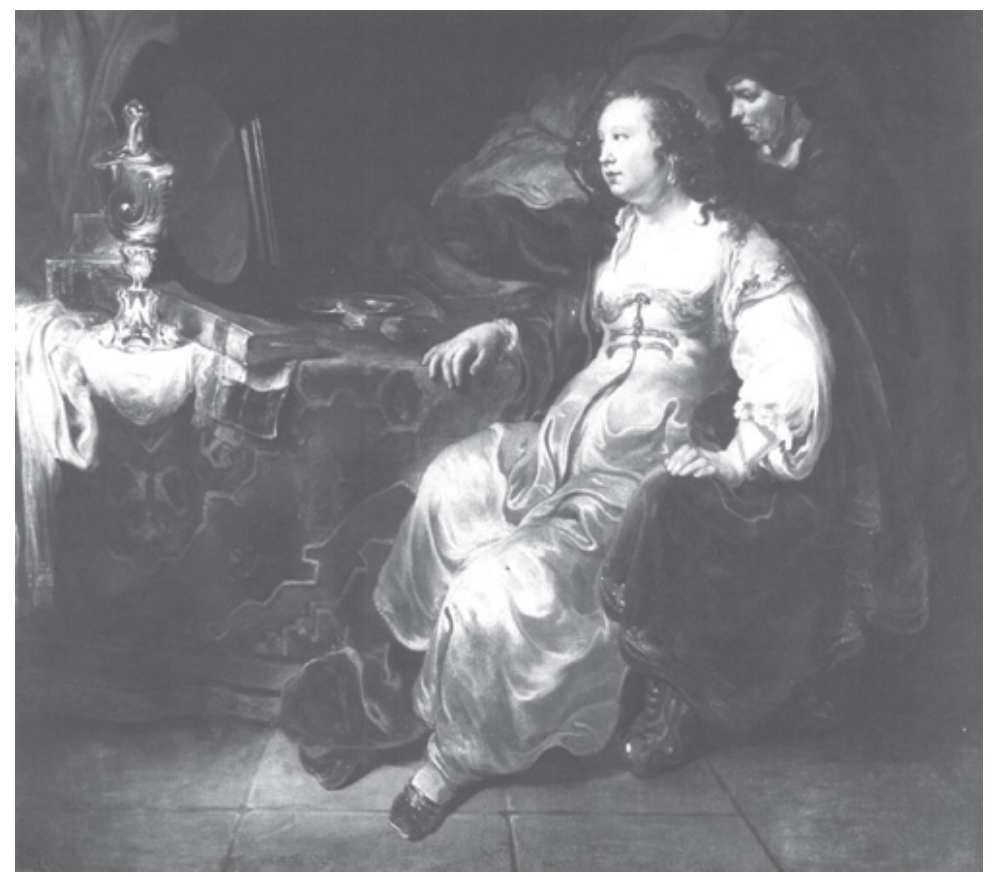

Fig. 9. Jan van Noordt, El aseo de Ester. Paradero desconocido; anteriormente en la Hallsborough Gallery de Londres.

fortaleza necesaria para vencer su miedo y la debilidad de los tres días de ayuno. A la vez recuerda los banquetes con vino que la reina prepara para su esposo ${ }^{33}$, origen de la fiesta judía de Purim, que conmemora la acción salvadora del pueblo llevada a cabo por Ester, una celebración jubilosa donde cada judío debe beber al menos una copa de vino y expresar vivamente su alegría por el triunfo frente a los enemigos de Israel. Rembrandt conocería bien la fiesta porque vivía en pleno barrio judío de Amsterdam.

El propio grabado realizado por dibujo de Stimmer muestra a Ester yendo a ver al rey, con apoyo en una de las criadas y con la otra detrás cogiendo el vestido. Ester porta corona, joyas, armiño y ricos vestidos. En el grabado de Rembrandt conocido como La novia judía (Fig. 8), que representa a Ester sentada habiendo recibido la copia del edicto, con los labios apretados en signo de determinación, frondoso pelo -que en la Ester de Ottawa está siendo arreglado tras el ayuno- y la diadema real.

Otros ejemplos del círculo de Rembrandt, además de los mencionados por Diéguez, confirman nuestra interpretación. Son El aseo de Ester o Ester preparándose

33 Los banquetes con vino están muy presentes en la historia de Ester: hay uno al comienzo, cuando Asuero, ebrio, manda llamar a su esposa Vasti (hay un lienzo del discípulo tardío de Rembrandt Aert de Gelder con este asunto), y Flavio Josefo (Flavij Josephi, op. cit. p. 180) hace mención de los banquetes que celebraron los judíos al conocer el triunfo de Ester y que se seguían haciendo en tiempos del historiador judeo-romano. 


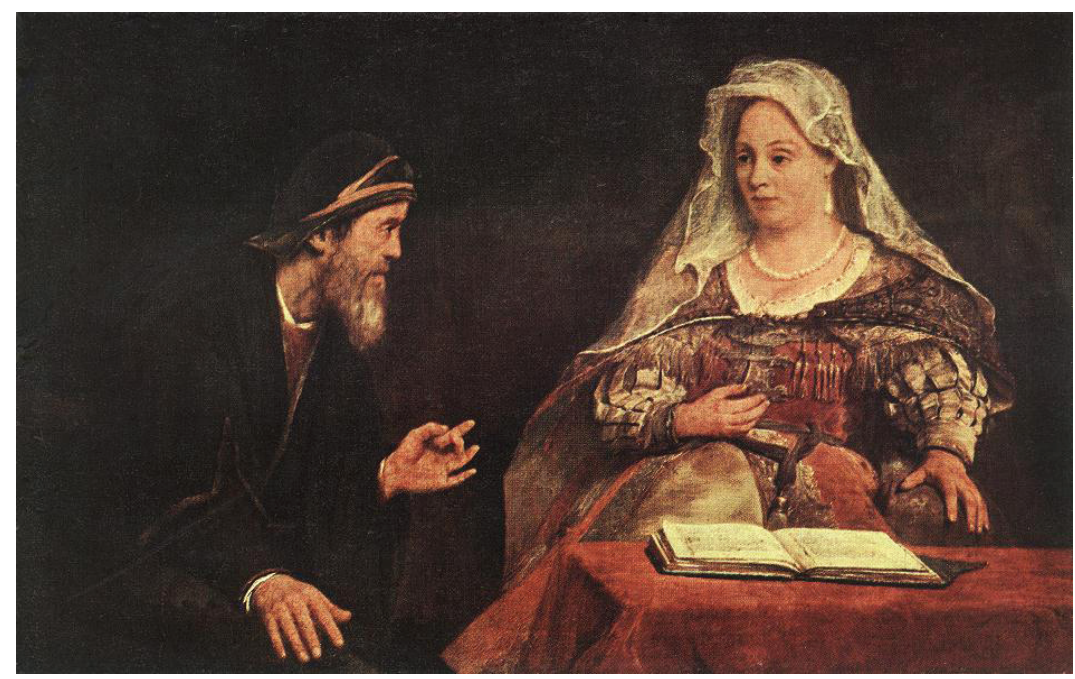

Fig. 10. Aert de Gelder, Ester y Mardoqueo, 1685. Museo de Bellas Artes de Budapest.

para aparecer ante Asuero (en paradero desconocido; anteriormente en la Hallsborough Gallery de Londres) del pintor de Amsterdam Jan van Noordt (1623-1681) (Fig. 9), que muestra la copa de plata con una forma semejante al caracol marino, copiando la famosa pieza de Adam van Vianen, el libro, el espejo, el cortinaje áulico, la arqueta con joyas o la sirvienta arreglando el pelo, y Ester y Mardoqueo (1685; Museo de Bellas Artes de Budapest) de Aert de Gelder (Fig. 10), en que aparecen, como en los demás ejemplos citados, el libro y el gesto de conformidad de Ester ${ }^{34}$.

Aunque se suele incluir esta pintura en la serie de mujeres fuertes de la Biblia y heroínas de la antigüedad clásica que Rembrandt pintó precisamente en sus primeros años en Ámsterdam, se trata de figuras únicas identificadas iconográficamente, y ésta, por el contrario, forma parte de una escena. El ejemplar madrileño es una pintura de mayor empeño que aquéllas, una escena con un hondo significado para quienes se sentían en situación semejante a la que dio lugar la heroicidad de Ester. Era un asunto especialmente apreciado por los calvinistas y otros protestantes, para los que Ester simbolizaba el triunfo del pueblo frente a las insidias del poderoso. En los países católicos, la historia de Ester tenía menor difusión y un significado muy diferente, puesto que prefiguraba la figura intercesora de la Virgen. Quizá por esta razón, al llegar a Nápoles, la figura rembrandtiana no fue reconocida como Ester y comenzó a denominarse Judit, asunto mucho más popular y frecuente en la pintura italiana y española.

34 DIÉGUEZ RODRÍGUEZ, op. cit., pp. 187-188, incluye la reproducción del gesto de la mano que significa aceptación según BULWER, John, Chirologia on the natural Language of the Hands, Londres, Thomas Harper, 1644, pp 88-89. El cuadro del Prado es anterior a esta publicación, lo que sugiere que se trataba de un gesto codificado desde tiempo atrás para significar entrega o conformidad. 